\title{
Parental satisfaction and perception of Progress in influencing the Practice of complementary health approaches in children with autism: a cross sectional survey from Negeri Sembilan, Malaysia
}

Jun Jean Ong (1)

\begin{abstract}
Background: Parents' use of complementary health approaches (CHA) for children with autism spectrum disorder (ASD) are common despite the uncertain evidence of its benefit. Parents often adopt CHA due to dissatisfaction with conventional treatment. This study aimed to examine parents' satisfaction with ASD treatment and their perception of progress in their child's development. Parents' use of CHA among children with ASD and the factors related were also evaluated.

Methods: Self-administered questionnaires were completed by 48 parents of children with ASD at a single tertiary referral hospital in Malaysia. Correlation analysis was used to explore associations between parental satisfaction scores, perception of progress scores and use of CHA.

Results: Use of CHA was reported by parents for $35.4 \%$ of children with ASD in the sample. Parents who were less satisfied with conventional treatment and parents who perceived poorer progress in their child's development were more likely to use CHA. Strong positive relationship was found between parent satisfaction with ASD treatment scores and parent perception of progress scores, which indicates that parents who were satisfied with treatment were more likely to perceive greater progress in their child's development. Improvement in child's progress was most appreciated by parents in their child's behavior (85.5\%), social skills (83.3\%) and motor skills (77.1\%).

Conclusion: The use of CHA was common among children with ASD. Parents were more likely to practice CHA when they were less satisfied with conventional treatment and perceived poorer progress. A larger multicenter study is required to further explore the practice of CHA among children with ASD throughout Malaysia.
\end{abstract}

Keywords: Autism spectrum disorder, Parent satisfaction, Complementary health approaches

\section{Background}

Autism Spectrum Disorder (ASD) is a neurodevelopmental disorder characterized by persistent deficits in social communication and interaction across multiple context with restricted, repetitive patterns of behavior, interests or activities [1]. One of the main factors contributing to the rise of ASD prevalence worldwide is the

Correspondence: OngJunJean@imu.edu.my

Pediatric Department, Clinical Campus Seremban, International Medical

University (IMU), Jalan Rasah, 70300 Seremban, Seri Menanti, Negeri Sembilan, Malaysia growing awareness among health professionals. In Malaysia, the publication of the first local clinical practice guideline on the Management of ASD (2014) have resulted in increasing number of children suspected with ASD referred for early diagnosis and interventions [2].

Management of ASD requires a combination of regular behavioral and educational interventions that manages the main symptoms of autism, and occasionally medications to manage coexisting medical and behavioral problems. A high number of trained occupational therapist, speech therapist, psychologist and doctors

C The Author(s). 2019 Open Access This article is distributed under the terms of the Creative Commons Attribution 4.0 International License (http://creativecommons.org/licenses/by/4.0/), which permits unrestricted use, distribution, and reproduction in any medium, provided you give appropriate credit to the original author(s) and the source, provide a link to the Creative Commons license, and indicate if changes were made. The Creative Commons Public Domain Dedication waiver (http://creativecommons.org/publicdomain/zero/1.0/) applies to the data made available in this article, unless otherwise stated. 
specializing in ASD are required to address the rising number of children diagnosed. In Malaysia, all children with ASD receiving services from the public funded hospitals are facing challenges with the limited numbers of occupational and speech therapist available. Thus, it is fundamental to promote parental training and parentmediated interventions to maximize the benefits of each treatment sessions [3]. The national clinical guidelines on Management of ASD equally emphasize on the importance of parental involvement to encourage continuity and application of learnt skills in the home environment. Parents has the advantage of recognizing changes early when monitoring treatment outcome due to their familiarity with their child's uniqueness [4].

\section{Factors influencing parent satisfaction with ASD treatment}

Parent satisfaction with treatment motivates parents to be actively involved in their child's care. Their perception of treatment and perceived effectiveness are often taken into consideration by healthcare providers for decision making on treatment modalities and treatment goals. Parent satisfaction is also frequently used as an indicator of service quality [5], especially so in-service orientated healthcare system which will further influence evaluation, treatment outcome and quality of healthcare [6-8]. Additionally, parents assist in providing information about the child's progress in functioning skills and behavior [4], therefore working alongside the therapist in deciding on treatment goals. Variability in characteristics and symptoms among children with ASD may also result in different treatment response. Treatment will most likely be discontinued if parents believe their child is not benefiting or making progress. Therefore, parents' involvement and perception of child's positive progress are essential to ensure adherence and strong parenttherapist alliance $[9,10]$.

\section{Services for ASD in Malaysia}

Children with clinical suspicion of ASD or fails the Modified Checklist for Autism in Toddlers (M-CHAT) that is integrated in the health record book, are being referred to the state referral hospital. Diagnosis of ASD is made based on the DSM V criteria through information collected from different sources and clinical judgements of the pediatrician. Children diagnosed are subsequently managed with the occupational and speech language pathologist available in the state hospitals or health clinics [2]. The most common interventions implemented by occupational therapist in Malaysia are play therapy, followed by sensory integration training, sensorimotor stimulation, preschool training, early intervention and Snoezelen therapy [11]. The frequency of treatment received are often below international recommendation and depends largely on the availability of the therapist [12]. In addition, many occupational therapists may not have received specialized training or certification in providing therapy to children with ASD [11]. Hence, parents from middle and higher income may decide to send their child for additional regular private treatment which are costly and not supported financially by the national healthcare [13].

\section{Complementary health approaches (CHA) in Malaysia}

Complementary medicine is defined by World Health Organization (WHO) as a broad set of health care practices that are not part of that country's own tradition or conventional medicine and are not fully integrated into the dominant health-care system [14]. In Malaysia, the term is used interchangeably with traditional medicine which are practices based on the theories, beliefs, and experiences indigenous to different cultures [14]. Hence, for the purpose of this study, CHA refers to all complementary and traditional practices designed to prevent, treat or manage ailment or illness or preserve the mental and physical well-being of an individual which includes traditional Malay practices, traditional Chinese or Indian practices, Islamic medical practices, homeopathy and other complementary therapies [15].

Parents seek for CHA due to various reasons. Many are influenced by their culture and traditions, believes that CHA is a safe natural method and are swayed by the easy accessibility of the products in the community [16]. It had also been postulated that parents' choice of CHA is based on their perceived cause of ASD $[17,18]$. Unconfirmed efficacy of CHA spreads extensively through word of mouth and is easily accepted by parents who are searching for treatment that promises cure. A 2009 national survey involving all age groups had reported that $\mathrm{CHA}$ was practiced by more than half $(55.6 \%)$ of the population to promote health, prevent and treat illness $[19,20]$. Biological based therapies (88.9\%) like herbs, supplements and vitamins are the most common CHA used followed by manipulative/ body-based practices $(27 \%)$ used to treat health problems [19]. However, the use of CHA among children in Malaysia is still unclear especially among children with ASD. Little is also known about the linkage between parent satisfaction, perception of progress and the use of CHA for children with ASD in Malaysia. Therefore, this study aimed to examine parent satisfaction with ASD treatment and their perception of progress in their child's development. Parents' use of CHA among children with ASD and the factors related were also evaluated.

\section{Methods}

Parents and caregivers of children below 18 years old diagnosed with ASD, who were attending the scheduled clinic appointment at Pediatric Clinic, Hospital Tuanku 
Jaafar were invited to participate. The hospital is a tertiary center that receives patient referrals from health clinics in the entire Negeri Sembilan state and its neighboring states in Malaysia. Newly diagnosed ASD within the last 6 months were excluded because it was felt that parents were not able to truly appreciate adequate progress in such a short time. During that period of time, the children may have attended two or three therapy session, which is too few for parents to build an objective opinion. Written informed consents were obtained and parents who agreed to participate were requested to complete a questionnaire. Questionnaires were mailed to parents of children who were not able to attend their appointment. A return stamped envelope was attached to encourage participation. Ethical approval was obtained from the Joint Committee of Research and Ethics of the International Medical University, Malaysia (IMU 389/ 2017) and Ethics Committee of National Malaysia Research Registry (NMRR-17-2521-37,205), prior to commencement of the study.

A total of 80 questionnaires were distributed. All of the 41 questionnaires distributed during the children's pediatric clinic follow up were completed. However, 8 out of 39 mailed were returned (20.5\% return rate). One questionnaire was not included due to incomplete data. The final completed questionnaires included in the study were 48.

\section{Study instrument}

A self-administered questionnaire which consist of 4 sections covering the demographic data of both parent and child (section A), parent satisfaction with ASD treatment and parent perception of child's progress (section $\mathrm{B}$ ), practice of private conventional treatment or complementary health approaches (section $\mathrm{C}$ ) and presence of comorbidities (section D) were distributed.

\section{Demographics}

Parents were requested to report their child's age, gender, ethnicity, number of siblings and family income. Information on household family income were grouped into 3 categories which consist of low (< MYR3000.00, equivalent to USD730.00), middle (MYR3001.00-10, 000.00, equivalent to USD730.00 - USD2400.00) and high (> MYR10000.00) income group. The range of income in each category were based on the Malaysian official statistic data [21]. The age when child was first suspected and diagnosed to have ASD, as well as the person who first raised the suspicion were also requested in this section.

\section{Parent ASD treatment satisfaction}

Parents were asked to indicate responses on a five point Likert scale ( $5=$ Strongly Agree to $1=$ Strongly Disagree) in response to the question stem 'I am happy with the treatment received by my child at....' followed by the unit involved (occupational therapy, speech therapy and pediatric clinic) which are based in the same public hospital. All three question items scores were summed to obtain the parent satisfaction scores.

\section{Treatment outcome}

The items evaluating parent perception of child's progress were adapted from previous studies $[9,22]$ Parents were asked to assess their child's progress in 6 areas of development in response to treatment which includes speech and language, behavior, focus and attention, cognitive, physical and fine motor and social. Each area was defined for parents. The parents were asked to rate the progress on a 5 -point Likert scale ( $5=$ Strongly Agree to $1=$ Strongly Disagree) in response to the question stem 'I notice improvement in my child's progress after treatment in the following areas....) followed by the developmental areas listed above. All six question items scores were summed to obtain the progress scores.

\section{ASD services}

Parents were asked if they were using CHA or have had used CHA in the past. Parents who did were than requested to list all treatment (not provided by the state hospital) they had practiced in the past and recently. A list of possible treatments, both private conventional treatments (e.g. occupational therapy, early intervention program, speech therapy) and CHA treatments (e.g. homeopathy, dietary supplements, massages, acupuncture, religious activities) were given to parents. The list was compiled from both local and overseas literature search to ensure completeness of the list [19, 20, 23]. Religious practices include prayers, faith healing and rituals that are practiced for the purpose of preserving health or treating illness.

\section{Parent's belief about cause of ASD}

Parents were asked about their perception of the cause of ASD. The list of causes was adapted from previous studies and were later grouped into unknown/genetic cause, medical related causes and non-medical causes $[17,24,25]$.

The questionnaire was piloted on 5 parents of children with ASD to ensure easy comprehension and appropriateness of the questions. Minimal adjustments to improved readibility were required.

\section{Statistical analysis}

Data collected were analyzed using SPSS version 25 . Descriptive statistics were used to describe the demographic data and parents' responses, in terms of frequencies and percentages. The continuous variables which 
Table 1 Characteristics of Parents and their Children with ASD

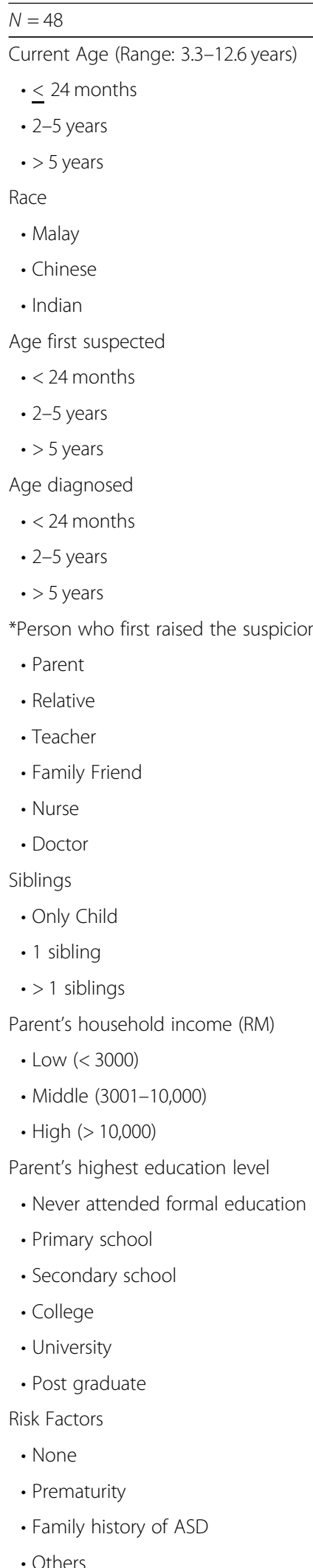

- Others

Body Mass Index (BMI)
Table 1 Characteristics of Parents and their Children with ASD (Continued)

\begin{tabular}{lll}
\hline$N=48$ & $\mathrm{n}$ & $\%$ \\
\hline - Underweight & 6 & 12.5 \\
• Normal & 34 & 70.8 \\
• Overweight/Obese & 8 & 16.7 \\
Co-morbid Conditions* & & \\
- None & 21 & 42.0 \\
• Global development delay/Intellectual disability & 11 & 22.0 \\
- Attention Deficit Hyperactivity Disorder (ADHD) & 10 & 20.0 \\
• Sleep issues & 4 & 8.0 \\
• Epilepsy & 1 & 2.0 \\
• Gastrointestinal issues & 1 & 2.0 \\
- Anxiety & 1 & 2.0 \\
• Others & 1 & 2.0
\end{tabular}

Therapy at Private centers $(n=16)^{*}$

• Early Intervention Programme/ Occupational therapy $\quad \begin{array}{lll}15 & 31.3\end{array}$

- Applied Behavioral Analysis $\quad 1 \quad 2.1$

- Tuition (One to one) $\quad 1 \quad 2.1$

- Swimming class $\quad 1 \quad 2.1$

$\begin{array}{lll}\text { - Art class } & 1 & 2.1\end{array}$

Parental Perception of the Causes of ASD*

• Unknown/ Genetic $\quad 3973.6$

- Medical related causes $\quad 4 \quad 7.5$

$\begin{array}{lll}\text { - Non-medical related causes } & 10 & 18.9\end{array}$

Number of Complementary Health Approaches Practiced

• None $\quad 31 \quad 64.6$

$\begin{array}{lll}\cdot 1 & 10 & 20.8\end{array}$

- 2 or more $\quad 7 \quad 14.6$

*Some have more than one answer, thus the total will not add up to $100 \%$

comprise of parent satisfaction scores and progress scores were analyzed by using Pearson correlation coefficient. Spearman's correlation was used for the other variables that do not fulfil the key assumptions of parametric test.

\section{Results}

The participants were 48 parents of 38 boys and 10 girls with ASD (Table 1). Their mean age were 6.1 years $(\mathrm{SD}=2.1)$. Questionnaires were mainly completed by the mothers $(n=40)$. Parents were the first person to raise the suspicion of ASD in $63.5 \%$ of the children, followed by teachers (9.6\%). Diagnosis of ASD were established in only $3(6.3 \%)$ children before the age of 24 months. Genetic factor and unknown reasons were frequently identified as the cause of ASD (73.6\%), followed by medicalrelated causes $(7.5 \%)$ such as pregnancy-related complication and nonmedical causes (18.9\%) which includes 
spiritual or magical reasons, excessive use of gadgets, vaccine and incorrect methods used in raising child.

Majority of parents were from lower (47.9\%) and middle (39.6\%) income group. Correlational result indicate that lower family income was significantly associated with lower parental education level $(\mathrm{r}=.610, p<.0001)$. One third (33.3\%) of children attended conventional therapy at private centers and were associated with higher family income $(\mathrm{r}=.325, p<0.05)$. The types of private treatment reported were early intervention program, occupational therapy and applied behavioral analysis therapy.

\section{Relationship between parent satisfaction with ASD treatment and perception of Progress}

The study found that most parents were highly satisfied with ASD treatment. 89.6 and $75 \%$ of parents rated a minimum good for both occupational and speech language therapy (Table 2). Parents' perception of their child's progress in different developmental areas were also positive, with the most progress seen in behavior $(85.5 \%)$ followed by social skills $(83.3 \%)$, physical and fine motor $(77.1 \%)$, speech and language $(75.1 \%)$, cognitive $(74.9 \%)$ and focus and attention (68.7\%) (Table 3). A large positive relationship between parent satisfaction with ASD treatment scores and progress scores were found, $\mathrm{r}=.699, p<.001$ (Table 4). In addition, the results showed that family income was inversely associated with parent satisfaction with ASD treatment scores, $(\mathrm{r}=-.391, p<0.01)$. Both parent satisfaction and progress scores were not significantly associated with gender, age diagnosed, parent education level and presence of comorbidities.

Relationship between complementary health approaches, parent satisfaction with ASD treatment and parent perception of Progress

Practice of CHA were reported in $35.4 \%$. The most common CHA were dietary supplements (32\%), massages (22\%), hot spring therapy (14\%), and religious activities (14\%) (Fig. 1). Correlational results indicated that there is a negative association between the use of CHA with parent satisfaction with ASD treatment scores and progress scores, $(\mathrm{r}=-.345, p<0.05)$ and $(\mathrm{r}=-.356, p<0.05)$ respectively. There was no association between parents' perception of the cause of ASD and the use of CHA.

\section{Discussion}

The study revealed that parents' perception of their child's progress in different areas of development were highly associated with parents' satisfaction with ASD conventional treatment. All parents hope to achieve meaningful and functional improvement in their child's behavior and development. Parents regard their child's progress as a reflection of treatment effectiveness. Therefore, regardless of the child's performance, if the parent's perception of progress is not aligned with the healthcare providers and considers treatment as ineffective, the parent will not be satisfied with the treatment provided. At times, parents and healthcare providers may have different views on the amount of progress expected and disagree on treatment plans. These differences exist because the degree of improvement is subjective and may be influence by beliefs and practices $[23,26]$. Perhaps parents' view their child's development at a different standpoint or reflects different priorities set among parents. However dissimilar the perceptions, it is still important to understand these differences because it will influence the parents' future decision surrounding treatment $[9,27]$. Lack of parents' perception of change and improvement are reported as common reasons parents discontinue treatment $[9,28]$. Therefore, shared decision making between both parents and healthcare providers, with consideration of parents' priorities, are vital to discuss mutual realistic treatment goals to prevent noncompliance and disheartenment [29].

In the present study, parents were less satisfied with speech language therapy, compared to the occupational therapy. The disparity may be due to infrequent number of sessions secondary to the lack of trained speech language pathologist in the country [30]. It had been reported in a local study that speech therapy is among the third highest service that is very much needed and highly unmet among children with disabilities [31].

Use of CHA among children with ASD in this study (35.4\%) were lower than the national statistics of $55.6 \%$ [19]. Previous local studies reported a higher use of CHA of $84.5 \%$ among children with cancer and $76 \%$ among children with inflammatory bowel disease [32, 33]. Perhaps parents of ASD children were more cautious when using CHA compared to parents of children with the above diseases. A small minority of parents may

Table 2 Responses of parents in rating their satisfaction towards treatment received

\begin{tabular}{|c|c|c|c|c|c|}
\hline Treatment & $\begin{array}{l}\text { Very Good } \\
\text { N (\%) }\end{array}$ & $\begin{array}{l}\text { Good } \\
\text { N (\%) }\end{array}$ & $\begin{array}{l}\text { Unsure } \\
N(\%)\end{array}$ & $\begin{array}{l}\text { Poor } \\
\text { N (\%) }\end{array}$ & $\begin{array}{l}\text { Very Poor } \\
N(\%)\end{array}$ \\
\hline Overall rating & $17(35.4)$ & $23(47.9)$ & $5(10.4)$ & $3(6.3)$ & 0 \\
\hline Occupational therapy & $24(50.0)$ & 19 (39.6) & $2(4.2)$ & $1(2.1)$ & $2(4.2)$ \\
\hline Speech and language therapy & $16(33.3)$ & $20(41.7)$ & $6(12.5)$ & $4(8.3)$ & $1(2.1)$ \\
\hline
\end{tabular}


Table 3 Responses of parents in rating their child's progress across developmental areas

\begin{tabular}{|c|c|c|c|c|c|}
\hline Developmental Area & $\begin{array}{l}\text { Very Good } \\
\text { N (\%) }\end{array}$ & $\begin{array}{l}\text { Good } \\
\text { N (\%) }\end{array}$ & $\begin{array}{l}\text { Unsure } \\
\mathrm{N}(\%)\end{array}$ & $\begin{array}{l}\text { Poor } \\
\text { N (\%) }\end{array}$ & $\begin{array}{l}\text { Very Poor } \\
N(\%)\end{array}$ \\
\hline Behavior & $15(31.3)$ & $26(54.2)$ & $3(6.3)$ & $1(2.1)$ & $3(6.3)$ \\
\hline Social & $12(25.0)$ & $28(58.3)$ & $4(8.3)$ & $2(4.2)$ & $2(4.2)$ \\
\hline Physical and fine motor & $16(33.3)$ & $21(43.8)$ & $7(14.6)$ & $1(2.1)$ & $3(6.3)$ \\
\hline Speech and language ${ }^{* *}$ & $15(31.3)$ & $21(43.8)$ & $5(10.4)$ & $3(6.3)$ & $3(6.3)$ \\
\hline Cognitive & $13(27.0)$ & $23(47.9)$ & $7(14.6)$ & $2(4.2)$ & $3(6.3)$ \\
\hline Focus and Attention & $10(20.8)$ & $23(47.9)$ & $11(22.9)$ & $2(4.2)$ & $2(4.2)$ \\
\hline
\end{tabular}

* Arrange from highest to lowest progress

** May not achieve $100 \%$ due to missing data

also be concern of the potential harm of the use of CHA [34] and only consider the option when truly necessary.

This study further showed that parents who perceived poorer progress in their child's development and less satisfied with conventional treatment were more likely to use CHA. This result is consistent with findings from other studies [20,35]. Parents are more likely to seek for treatment options like CHA that is easily accessible, cheaper and accepted by the community [35]. The use of $\mathrm{CHA}$ is further promoted by the perception that $\mathrm{CHA}$ is a safer 'natural' method that treats the cause, not just the symptoms of ASD and promotes resolution in core symptoms of ASD [18, 35, 36]. The commonest types of CHA used in this study were herbal and vitamin supplements, which were similar to practices in the local and Western population [35]. Religious activities were practiced by $14 \%$ of parents, however the nature of the religious activities were not explored in this study and may be underreported as a treatment method due to its integration into daily religious practices. A local study reported on the frequent use of spiritual therapy among Malaysian population, which comprise of faith healing or prayer that is strongly influenced by religion and culture [20]. According to the national policy guidelines on traditional and complementary medicine, spiritual therapies practiced for the purpose of restoring or maintaining health are recognized as a type of traditional medicine [37]. Homeopathy is a common practice among the Malay ethnic group in Malaysia, however it was reported to be surprisingly low in this study. The use of homeopathy was consistently found to be low in another local study among Malaysian population, and it was postulated that majority of participants may not have described the type of CHA used accurately thus wrongly categorized [19].

An association between parental beliefs on the cause of autism and the choice of CHA were not appreciated in this study [17]. This is perhaps due to the parents' willingness to try all forms of treatment within their means regardless of their own beliefs. Additional factors that may have influence their choice of treatment were not explored here. Parents may also be pressured to use CHA due to the lack of established treatment options, high cost of conventional therapy and lack of transportation [38]. It had been reported that the cost of therapy at private occupational therapy centers may be as high as MYR 600 (estimated USD 150) per month or higher if more sessions are required, thus limiting the number of families that are able to afford private conventional treatment [13]. Although the cost of CHA may be high too, the range varies widely depending on the type of product or intervention and qualification of the practitioner, which allows more flexibility among parents of all income groups.

The small sample size was a limitation to this study. However, this is an exploratory study that may spur future research to investigate the factors influencing outcome of children in response to ASD treatment and the

Table 4 Correlation of parental satisfaction and child's progress scores with related factors

\begin{tabular}{|c|c|c|c|c|c|}
\hline & Satisfaction scores & Progress Scores & Family Income & Treatment at Private Centre & Use of $\mathrm{CHA}$ \\
\hline Satisfaction scores & 1 & $.699 * *$ & $-.391^{*}$ & -.097 & $-.345^{*}$ \\
\hline Progress Scores & & 1 & -.158 & -.082 & $-.356^{*}$ \\
\hline Family Income & & & 1 & $.325^{*}$ & .010 \\
\hline Treatment at Private Centre & & & & 1 & .063 \\
\hline Use of $\mathrm{CHA}$ & & & & & 1 \\
\hline
\end{tabular}

${ }^{*} p<0.05$

$* * p<0.001$ 


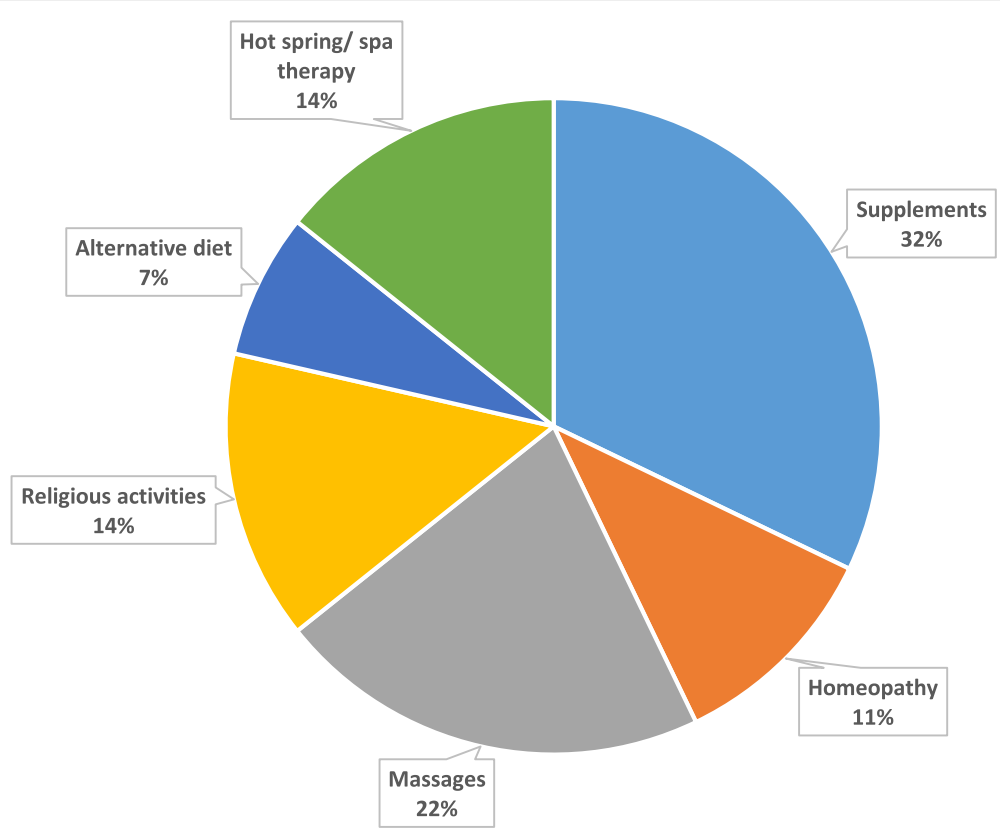

Fig. 1 Complementary Health Approaches (CHA) Among Children with ASD

effectiveness of specific CHA in children with ASD. This study represented mainly middle and lower income group families and may not reflect children who were attending private medical centers. In addition, parents who were non-compliant to treatment and perhaps less satisfied with ASD treatment were also underrepresented as indicated by the poor return rate of the mailed questionnaires. The possibility of response bias among the parents who participated during their clinic appointments cannot be totally ignored and may be reduced by mailing all questionnaires to all participants. However, it was not implemented due to the predicted lack of response. Healthcare providers were also encouraged to enquire about the use of CHA and to allow parents to speak freely without feeling the need to hide the information.

\section{Conclusion}

This study is the first to investigate parents' satisfaction and perception of progress in children with ASD in Malaysia. The findings of its strong association further reinforce the importance of selecting therapy that focuses on parents' outcome goals and interventions that highlights a particular target skill. A future systematic qualitative research will enlighten us on additional variables that may influence parental satisfaction. In addition, the practice of CHA is common among children with ASD in our center. However, this finding should be further ascertain by future studies exploring the actual prevalence of CHA among children with ASD at national level and identify additional contributory factors that leads to the adoption of CHA.

\section{Abbreviations}

ASD: Autism Spectrum Disorder; CHA: Complementary Health Approaches; M-CHAT: Modified Checklist for Autism in Toddlers

\section{Acknowledgements}

I would like to show my gratitude to the nurses and doctors who had supported me during the collection of data. Special thanks to Dr. Meenal Mavinkurve for her constructive ideas and support and Dr. Sangeetha Shyam for her guidance on statistical analysis.

\section{Author's contributions}

JJO constructed and revised the questionnaire, analyzed the data and wrote the manuscript. The author read and approved the final manuscript.

\section{Funding}

This study was supported by International Medical University (IMU 389/2017). The funding source had no role in study design, data collection and analysis, data interpretation and writing of the manuscript.

\section{Availability of data and materials}

The datasets used and analyzed during the current study are available from the corresponding author on reasonable request.

\section{Ethics approval and consent to participate}

This study was approved by the Joint Committee of Research and Ethics of the International Medical University, Malaysia. Written informed consent were obtained from the parents of the participants.

\section{Consent for publication}

Not applicable.

\section{Competing interests}

The author declare that she has no competing interests.

Received: 2 December 2018 Accepted: 3 September 2019

Published online: 09 September 2019

\section{References}

1. Hoffman L. Book Essay on Diagnostic and Statistical Manual of Mental Disorders; Desk Reference to the Diagnostic Criteria from DSM-5Diagnostic and Statistical Manual of Mental Disorders, 5th Edition. Washington, DC: 
American Psychiatric Association, 2013, 991 pp. Desk Reference to the Diagnostic Criteria from DSM-5. Washington, DC: American Psychiatric Association, 2013, 443 pp. Journal of the American Psychoanalytic Association [Internet]. SAGE Publications; 2014 Feb;62 (1):125-47; https://doi. org/10.1177/0003065114524985

2. Clinical Practice Guideline (CPG) Ministry of Health (MOH), Management of Autism Spectrum Disorder in Children and Adolescents. 2014. Available from: http://www.acadmed.org.my

3. Divan G, Hamdani SU, Vajartkar V, Minhas A, Taylor C, Aldred C, et al. Adapting an evidence-based intervention for autism spectrum disorder for scaling up in resource-constrained settings: the development of the PASS intervention in South Asia. Global Health Action [Internet] Informa UK Limited. 2015;8(1):27278. https://doi.org/10.3402/gha.v8.27278.

4. Burrell TL, Borrego Jr J. Parents' Involvement in ASD treatment: what is their role? Cogn Behav Pract 2012 Aug 1;19(3):423-432; https://doi.org/10.1016/j. cbpra.2011.04.003.

5. Edlund MJ, Young AS, Kung FY, Sherbourne CD, Wells KB. Does Satisfaction Reflect the Technical Quality of Mental Health Care? Health Services Research [Internet]. Wiley; 2003;38(2):631-45; https://doi.org/10.1111/14756773.00137

6. Minnes P, Steiner K. Parent views on enhancing the quality of health care for their children with fragile $X$ syndrome, autism or Down syndrome. Child: Care, Health and Development [Internet]. Wiley; 2009;35(2):250-6; https:// doi.org/10.1111/j.1365-2214.2008.00931.x

7. Geiger DM, Smith DT, Creaghead NA. Journal of Autism and Developmental Disorders [Internet] Springer Nature; 2002;32(4):307-12; https://doi.org/10. 1023/a:1016382819186.

8. Tierney E, Aman M, Stout D, Pappas K, Arnold LE, Vitiello B, et al. Parent satisfaction in a multi-site acute trial of risperidone in children with autism: a social validity study. Psychopharmacology [Internet]. Springer Nature; 2006;191(1):149-57; https://doi.org/10.1007/s00213-006-0604-z

9. Bowker A, D'Angelo NM, Hicks R, Wells K. Treatments for Autism: Parental Choices and Perceptions of Change. Journal of Autism and Developmental Disorders [Internet]. Springer Nature; 2010;41(10):1373-82; https://doi.org/10. 1007/s10803-010-1164-y

10. Stadnick NA, Drahota A, Brookman-Frazee L. Parent Perspectives of an Evidence-Based Intervention for Children with Autism Served in Community Mental Health Clinics. Journal of Child and Family Studies [Internet]. Springer Nature; 2012;22(3):414-22; https://doi.org/10.1007/s10826-0129594-0

11. Kadar M, McDonald R, Lentin P. Malaysian occupational therapists' practices with children and adolescents with autism spectrum disorder. British Journal of Occupational Therapy [Internet]. SAGE Publications; 2015;78(1): 33-41; https://doi.org/10.1177/0308022614561237

12. Zwaigenbaum L, Bauman ML, Choueiri R, Kasari C, Carter A, Granpeesheh D, et al. Early intervention for children with autism spectrum disorder under 3 years of age: recommendations for practice and research. Pediatrics. 2015; 136(Supplement 1):S60-81.

13. Fikry A, Hassan H. Characteristics of. Autism Center in Malaysia EnvironmentBehaviour Proceedings Journal [Internet] e-IPH Ltd. 2016;1(4):75. https://doi. org/10.21834/e-bpj.v1i4.173.

14. World Health Organization. Traditional, complementary and integrative medicine. https://www.who.int/traditional-complementary-integrativemedicine/about/en/ Assessed on 2 May 2019.

15. Traditional and Complementary Medicine Division, Ministry of Health Malaysia: Traditional and Complementary Medicine Blueprint 2018-2027 Health Care. http://tcm.moh.gov.my/ms/upload/Blueprint.pdf

16. Hanson E, Kalish LA, Bunce E, Curtis C, McDaniel S, Ware J, et al. Use of Complementary and Alternative Medicine among Children Diagnosed with Autism Spectrum Disorder. Journal of Autism and Developmental Disorders [Internet]. Springer Nature; 2006;37(4):628-36; https://doi.org/10.1007/ s10803-006-0192-0

17. Ravindran N, Myers BJ. Cultural Influences on Perceptions of Health, Illness, and Disability: A Review and Focus on Autism. Journal of Child and Family Studies [Internet]. Springer Nature; 2011;21(2):311-9; https://doi.org/10.1007/ s10826-011-9477-9

18. Levy SE, Hyman SL. Novel treatments for autistic spectrum disorders. Mental Retardation and Developmental Disabilities Research Reviews [Internet]. Wiley; 2005;11(2):131-42; https://doi.org/10.1002/mrdd.20062

19. Siti ZM, Tahir A, Farah Al, Fazlin SMA, Sondi S, Azman AH, et al. Use of traditional and complementary medicine in Malaysia: a baseline study.
Complementary Therapies in Medicine [Internet] Elsevier BV. 2009 Oct;17(56):292-9. https://doi.org/10.1016/j.ctim.2009.04.002.

20. Sivadasan S, Ali AN, Lin LW, Balakrishnan D, Ramachandran S, Dhanaraj SA. Use of complementary and alternative medicine in the population of Kedah Darul Aman, Malaysia. International Journal of Pharmaceutical Sciences \& Research. 2014;5(4):1263-73.

21. Department of Statistics Malaysia Official Portal. Report of household income and basic amenities survey 2016. https://www.dosm.gov.my/v1

22. Hume K, Bellini S, Pratt C. The Usage and Perceived Outcomes of Early Intervention and Early Childhood Programs for Young Children With Autism Spectrum Disorder. Topics in Early Childhood Special Education [Internet]. SAGE Publications; 2005;25(4):195-207; https://doi.org/10.1177/ 02711214050250040101

23. Goin-Kochel RP, Mackintosh VH, Myers BJ. Parental reports on the efficacy of treatments and therapies for their children with autism spectrum disorders. Research in Autism Spectrum Disorders [Internet]. Elsevier BV; 2009;3(2):52837; https://doi.org/10.1016/j.rasd.2008.11.001

24. Mercer L, Creighton S, Holden JJA, Lewis MES. Parental perspectives on the causes of an autism spectrum disorder in their children. J Genet Couns. 2006;15(1):41-50. https://doi.org/10.1007/s10897-005-9002-7.

25. Goin-Kochel RP, Myers BJ. Congenital versus regressive onset of autism spectrum disorders: Parents' beliefs about causes. Focus on Autism and Other Developmental Disabilities. 2005;20(3):169-79. https://doi.org/10.1177/ 10883576050200030501

26. Bernheimer LP, Weisner TS. "Let me just tell you what I do all day...."infants \& Young children [internet]. Ovid Technologies (Wolters Kluwer Health). 2007 Jul;20(3):192-201. https://doi.org/10.1097/01.iyc.0000277751.62819.9b.

27. Murray DS, Ruble LA, Willis H, Molloy CA. Parent and teacher report of social skills in children with autism Spectrum disorders. Language speech and hearing Services in Schools [Internet]. American Speech Language Hearing Association; 2009 1;40(2):109. https://doi.org/10.1044/0161-1461(2008/070089).

28. Dillenburger K, Keenan M, Gallagher S, McElhinney M. Parent education and home-based behaviour analytic intervention: an examination of parents' perceptions of outcome. Journal of Intellectual \& Developmental Disability [Internet] Informa UK Limited. 2004 Jun;29(2):119-30. https://doi.org/10. 1080/13668250410001709476.

29. Levy SE, Frasso R, Colantonio S, Reed H, Stein G, Barg FK, et al. Shared decision making and treatment decisions for Young children with autism Spectrum disorder. Academic Pediatrics [Internet] Elsevier BV. 2016 Aug; 16(6):571-8. https://doi.org/10.1016/j.acap.2016.04.007.

30. Ahmad K. Discharging patients: a perspective from speech-language pathologists working in public hospitals in Malaysia. International Journal of Speech-Language Pathology. 2010;12(4):317-9. https://doi.org/10.3109/ 17549507.2010.483017.

31. Tan SH. Unmet health care service needs of children with disabilities in Penang, Malaysia. Asia Pacific Journal of Public Health. 2015;27(8_suppl): 41S-51S. https://doi.org/10.1177/101053951559246.

32. Hamidah A, Rustam ZA, Tamil AM, Zarina LA, Zulkifli ZS, Jamal R. Prevalence and parental perceptions of complementary and alternative medicine use by children with cancer in a multi-ethnic southeast Asian population. Pediatr Blood Cancer. 2009;52(1):70-4. https://doi.org/10.1002/pbc.21798.

33. Ong F, Lee WS, Lin C, Ng RT, Wong SY, Lim SL, Quak SH, Aw M. Complementary and alternative medicine (CAM) practices and dietary patterns in children with inflammatory bowel disease in Singapore and Malaysia. Pediatrics \& Neonatology. 2018;59(5):494-500. https://doi.org/10. 1016/j.pedneo.2017.12.007.

34. Ramdzan SN, Pinnock H, Liew SM, Sukri N, Salim H, Hanafi NS, Hussein N, Suhaimi J, Lee PY, Cheong AT, Ahad AM. Perceptions of complementary/ alternative medicine use and influence on evidence-based asthma medicine adherence in Malaysian children. NPJ primary care respiratory medicine. 2019;29(1):5. https://doi.org/10.1038/s41533-019-0118-x.

35. Lindly OJ, Thorburn S, Heisler K, Reyes NM, Zuckerman KE. Parents' Use of Complementary Health Approaches for Young Children with Autism Spectrum Disorder. Journal of Autism and Developmental Disorders [Internet]. Springer Nature; 2017:48(5):1803-18; https://doi.org/10.1007/ s10803-017-3432-6.

36. Levy SE, Hyman SL. Complementary and alternative medicine treatments for children with autism Spectrum disorders. Child and Adolescent Psychiatric Clinics of North America [Internet] Elsevier BV. 2015;24(1):117-43. https://doi. org/10.1016/j.chc.2014.09.004. 
37. Traditional and Complementary Medicine Division, Ministry of Health (MOH), National Policy of Traditional and Complementary Medicine. 2007. Available from: http://tcm.moh.gov.my/en/upload/NationalPolicy.pdf.

38. Carlon S, Carter M, Stephenson J. Erratum to: "A review of declared factors identified by parents of children with autism spectrum disorders (ASD) in making intervention decisions" [Res. Autism Spectrum Disord. 7 (2013) 369-

381]. Research in Autism Spectrum Disorders [Internet]. Elsevier BV; 2013;

7(3):502-3; https://doi.org/10.1016/j.rasd.2013.01.001

\section{Publisher's Note}

Springer Nature remains neutral with regard to jurisdictional claims in published maps and institutional affiliations.

Ready to submit your research? Choose BMC and benefit from:

- fast, convenient online submission

- thorough peer review by experienced researchers in your field

- rapid publication on acceptance

- support for research data, including large and complex data types

- gold Open Access which fosters wider collaboration and increased citations

- maximum visibility for your research: over $100 \mathrm{M}$ website views per year

At $\mathrm{BMC}$, research is always in progress.

Learn more biomedcentral.com/submissions 